\title{
Reconhecimento, desreconhecimento e demarcaç̃ão simbólica: uma contribuiç̣̃o conceitual à análise do lado negativo do reconhecimento
}

\section{Luiz Gustavo da Cunha de Souza*}

\section{Resumo}

O presente artigo tem por objetivo central esboçar uma discussão teórica a respeito de relações de demarcação e hierarquização simbólicas que poderiam ser descritas por meio da categoria analítica de desreconhecimento. Este conceito, que será apresentado em relação aos recentes debates sobre a teoria do reconhecimento, conforme formulada por Axel Honneth, e sobre o lado negativo das relações de reconhecimento, visa explicitar formas de exercício do poder por meio das quais grupos privilegiados denegam a outros grupos ou indivíduos a possibilidade de participar em condições de igualdade das esferas institucionais de reconhecimento que legitimam as sociedades modernas. Neste sentido, as práticas e discursos de desreconhecimento representam uma negação intencional ou uma tentativa de solapar a aplicação dos princípios implícitos do liberalismo democrático e universalista, conforme pressuposto na tradição teórica do reconhecimento. Particular atenção será dada a dois casos de corrosão das normas implícitas de reconhecimento: em primeiro lugar, serão expostas formas de animosidade que buscam justificar estas

\footnotetext{
* Universidade Federal de Santa Catarina, Florianópolis, SC, Brasil.
} 
práticas por meio do recurso à constituição de um imaginário sobre grupos diferentes, assim atribuindo a estes últimos certas características negativas; em segundo lugar, serão trabalhados alguns exemplos da tradição do pensamento social brasileiro e de um eventual aguçamento das tensões políticas e de suas consequências para as tentativas de demarcação simbólica observadas no país.

Palavras-chave: Reconhecimento; Desreconhecimento; Demarcação simbólica; Animosidade dirigida a grupos; Subcidadania.

\section{Recognition, derecognition, and symbolic demarcation: a conceptual contribution to the analysis of the negative dimension of recognition}

\section{Abstract}

The aim of this article is to prospectively review forms of symbolic demarcation based on the analytical category of derecognition. in Axel Honneth's theory of recognition but departs significantly from it. Thanks to this movement, it will be able to pay attention to the often overlooked dimension of negative relations of recognition, in which privileged groups or individuals manage to exert social power over other groups or individuals, whose social position is weaker, thus impeding these latter totake part on the symbolic spheres of recognition, which build up modern societies. Accordingly, such practices of symbolic demarcation of social barriers will be exposed as tendencies towards the undermining of the normative core of modernity (namely, its principles of equality and participation). Two cases will be exposed at length, in order to make the situation understandable: the problem of group stereotyping through group-focused animosity and the problem of second-class citizenship in Brazil.

Keywords: Recognition; derecognition; Symbolic demarcation; Group-based animosity; Second-class citizenship.

\section{Introdução}

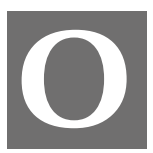

presente artigo tem como objetivo sugerir uma possível contribuição conceitual para o estudo de relações e discursos de diferenciação simbólica, a partir de uma crítica a certas limitações das categorias utilizadas por Axel Honneth no desenvolvimento de sua teoria do reconhecimento. A esta contribuição conceitual será dado o nome de 
desreconhecimento. Particularmente caro a esta perspectiva é o estudo de formas de justificação para o estabelecimento de barreiras simbólicas que visam intencionalmente solapar aquilo que Honneth (2003b) teorizou como uma teia intersubjetiva de relações de reconhecimento recíproco através da qual se legitimam as formas de sociabilidade modernas. Estas práticas de desreconhecimento do valor de outros indivíduos ou de outros grupos servem, pois, ao estabelecimento de hierarquias simbólicas que procedem à corrosão daquilo que poderia ser reconstruído como o princípio organizador das sociedades modernas, isto é, o reconhecimento implícito, que se desdobra no potencial para a afirmação do respeito universal e da solidariedade generalizada (Honneth, 2011a). Baseado nas premissas da obra mais recente de Honneth, porém afastando-se significativamente de suas conclusões, este artigo procura se apropriar das contribuições de Cillian McBride (2013) para o estudo da fenomenologia do reconhecimento e, através disso, apontar para uma dimensão eminentemente sociológica das disputas cotidianas por reconhecimento. Desse modo, espera-se descrever as relações de reconhecimento como uma disputa pelo exercício do poder social, a partir de intenções e interesses presentes nas relações interpessoais e na forma como eventualmente são representadas categorias associadas à noção de reconhecimento, como por exemplo: grupo, outro, identidade e diferença. Assim, ao invés da intenção reconstrutiva associada por Honneth à versão mais recente de sua teoria do reconhecimento, o que este artigo propõe é a ideia de que a arquitetura teórica do reconhecimento também serve ao diagnóstico de um tipo particular de prática, um tipo de prática que se desdobra no sentido oposto ao da institucionalização dos pressupostos normativos assumidos por Honneth. ${ }^{1}$

Na medida, porém, em que aquelas representações relacionadas ao reconhecimento serão analisadas à luz do estabelecimento de hierarquias

${ }^{1}$ Franciele Petry discutiu e comentou uma versão prévia do texto, tornando-o certamente melhor, por isso lhe agradeço. O texto também recebeu comentários de três pareceristas anônimos que, entre outras coisas relevantes, chamaram atenção para o fato de que deveria ficar claro desde o título que este artigo trata de uma revisão bibliográfica e não de uma análise empírica. Já os erros que persistem são apenas meus. 
simbólicas, as categorias mencionadas acima serão utilizadas como elementos de disputa por autoridade normativa - e não como categoria da integração apenas. Aqui, pois, deve ser feita a advertência de que a tentativa de conceitualizar a ação política a partir das categorias da teoria do reconhecimento de Honneth não implica qualquer referência à ideia de reconhecimento cultural, como o faz Nancy Fraser (2003a), pois, como lembram Saavedra e Sobottka (2009), Fraser interpreta a teoria de Honneth equivocadamente, aproximando-a do modelo comunitarista de Charles Taylor (2009). Todavia, ao entender o conceito de reconhecimento a partir de sua tradução como um fenômeno da vida social, procura-se aqui um afastamento da dimensão normativa que a filosofia atribui a este conceito, que é o que faz Honneth em seus trabalhos recentes (2011a; 2014). Nesse sentido, entende-se que a dimensão política aberta à compreensão a partir das categorias do reconhecimento não é aquela da identidade individual ou coletiva, mas a da mobilização de justificativas morais para a atribuição ou a denegação de reconhecimento. Por isso, a dimensão diagnóstica aludida anteriormente busca recuperar o projeto original da teoria honnethiana, o de descrever uma gramática moral dos conflitos sociais (Honneth, [1994] 2003a), aproximando-a da formulação de McBride, para quem as lutas por reconhecimento são, acima de tudo, lutas levadas a cabo por grupos ou indivíduos visando o estabelecimento de autoridade normativa para suas respectivas posições sociais.

A fim de cumprir esses objetivos, este artigo é divido em três partes. Em primeiro lugar, será apresentada a teoria de Honneth e, por meio de uma breve revisão bibliográfica, certas limitações da teoria do reconhecimento quanto à apreensão da dimensão negativa do reconhecimento serão trazidas à luz (I). A partir destas limitações será caracterizada conceitualmente uma aproximação entre este lado negativo do reconhecimento e práticas de demarcação simbólica (II). Na terceira seção, exemplos dessas práticas serão expostos de modo a esclarecer o tipo de prática referida aqui quando se utiliza o conceito de desreconhecimento (III). Apesar desses exemplos, porém, este artigo trata somente da dimensão conceitual das práticas que se 
pretende caracterizar como desreconhecimento. Assim, pretende-se iniciar avaliando os méritos e limites da teoria reconstrutiva de Honneth, colocando em questão seu pressuposto das normas implícitas de reciprocidade como sustentáculo da modernidade. Ao final, espera-se que a partir desta crítica o artigo contribua para a discussão sobre a melhor maneira de caracterizar tensões e disputas do ponto de vista da teoria do reconhecimento.

\section{Reconhecimento e sua ausência}

No debate entre Nancy Fraser e Axel Honneth (Fraser 2003a; 2003b; Honneth, 2003b; 2003c), ambos concordam que o conceito de reconhecimento se tornou central nos debates políticos e filosóficos do final do século XX. Esta concordância, porém, esconde o fato de que Fraser e Honneth discordam sobre onde deve ser colocada a ênfase da análise. Para Fraser (2003a; 2003b), o conceito de reconhecimento revela que importantes distorções na distribuição de bens materiais e simbólicos sobrevivem às políticas que visam corrigir as desigualdades de classe. Assim, a partir da ideia de reconhecimento, seria possível desenvolver eixos corretivos de desigualdades materiais e simbólicas, dependendo de qual o aspecto mais prejudicado em determinada situação. À solução perseguida por meio deste projeto metodológico, ela dá o nome de paridade de participação e afirma que, através dela, políticas de reconhecimento poderiam ser implementadas sem desalojar as ainda necessárias políticas de redistribuição material. Desse modo, por um lado, seria evitada uma convergência perversa entre as lutas por reconhecimento e as políticas neoliberais (Fraser, 1995) e, por outro, seria evitada uma ênfase excessiva na psicologia do reconhecimento. Ambas as tendências são atribuídas por Fraser à obra de Honneth.

De fato, Honneth inicia a construção de sua teoria do reconhecimento por meio de uma crítica à incapacidade de autores associados à Teoria Crítica da sociedade, de Max Horkheimer a Michel Foucault passando por Theodor Adorno e Jürgen Habermas, de perceberem os espaços de atividade pré-teórica dos sujeitos, isto é, espaços nos quais as intenções dos 
sujeitos se desenvolvem em referência a normas e valores intersubjetivos à margem das forças de dominação social. Neste espaço pré-teórico, Honneth identifica, seguindo a filosofia de Hegel, um momento de estabelecimento de relações intersubjetivas pautadas pelo reconhecimento recíproco (2003a). $\mathrm{Na}$ medida em que este reconhecimento recíproco é o que permite aos sujeitos identificarem a si mesmos como sujeitos a partir da confirmação de seu reconhecimento por um outro sujeito, Honneth vê neste conceito uma necessidade fundamental para o desenvolvimento bem-sucedido da personalidade individual. Este entendimento é compartilhado por Charles Taylor (2009), outro autor a trabalhar na tradição hegeliana. Taylor, porém, desdobra desta necessidade moral do reconhecimento a sugestão de uma política multiculturalista segundo a qual as identidades autonarradas dos sujeitos deveriam ser o critério normativo para arranjos institucionais. Honneth, por sua vez, nunca vai tão longe - e efetivamente afasta-se gradualmente de qualquer posição comunitarista, como se verá adiante; para ele, a implicação maior da necessidade moral do reconhecimento é que uma teoria social deveria estar atenta à dimensão de conflito intersubjetivo que os indivíduos carregam consigo para as esferas institucionais de ação coletiva. Dessa forma, assim como nas relações íntimas de amor e amizade, as esferas do direito público universal e da divisão do trabalho meritocrática são espaços nos quais os sujeitos envolvidos demandam e lutam pelo reconhecimento implícito de seus pares (2003a; 2003b). Em cada uma destas esferas, porém, Honneth identifica uma prática de desrespeito correspondente: o desrespeito do amor seria expresso na violência física que impede um sujeito de dispor de seu próprio corpo, como na tortura ou na violência não consentida; o desrespeito ao direito seria expresso na denegação de direitos; e o desrespeito à demanda por estima social seria expressa em práticas de humilhação que produzem vergonha social (Honneth, 2003a, cap. 6). Inicialmente, essas práticas de desrespeito podem funcionar como ponto de partida para a formulação da categoria do desreconhecimento, porque são descritas por Honneth como momentos de uma gramática moral dos conflitos sociais, isto é, situações cuja ocorrência possibilita uma articulação coletiva da luta por reconhecimento; 
mais ainda, esta articulação coletiva enquanto luta só é possível porque o reconhecimento ocorre como afirmação de uma expectativa, mas uma afirmação posterior à experiência prática, via de regra vivenciada por quem é levado a lutar por reconhecimento como formas de desrespeito. Justamente aqui, e este ponto será tratado mais adiante, há uma diferença fundamental com o trabalho posterior de Honneth: se lá o reconhecimento é, de fato, um traço implícito das sociedades modernas, aqui ele é, antes, o resultado de expectativas que participam daquela gramática de conflitos. Resumindo, em Luta por reconhecimento, o reconhecimento é posterior à luta, em $O$ direito da liberdade, será mostrado que é prévio. Mais que uma passagem da sociologia à filosofia normativa, esta mudança é importante, porque revela que, neste momento, ainda não se fala de desreconhecimento como negação ou desconstrução de algo implícito, mas como bloqueio a expectativas. Não por acaso, o vocabulário aqui é o do desrespeito (e não o da patologia), mesmo quando Honneth trata de invisibilidade (Honneth, 2003b): neste caso, ao invés de enfatizar o processo de invisibilização, Honneth foca nos efeitos do processo para o desenvolvimento integral da personalidade individual. Todavia, se alguns elementos da forma como Honneth concebe a dinâmica social do desrespeito já permitem aludir a formas de denegação do reconhecimento presentes naquilo que se chamará de desreconhecimento, particularmente a relação entre reconhecimento e moral (Honneth, 2000; Honneth, 2007)², há uma diferença fundamental entre este diagnóstico e aquele do desreconhecimento: é que, aqui, Honneth foca sua descrição em contextos institucionais que podem ser abertos às demandas morais de grupos que clamam por reconhecimentos, de modo que seu esquema das três formas de desrespeito carece justamente de um espaço para a dimensão fenomenológica da construção da realidade que bloqueia formas

${ }^{2}$ Agradeço à(ao) parecerista anônima(o) de Sociologias a dupla recomendação de notar algumas similaridades entre o primeiro diagnóstico de Honneth e a ideia de desreconhecimento e, também, por chamar minha atenção para os artigos em que Honneth lida diretamente com a relação entre moral e reconhecimento, particularmente interpretando esta relação na chave de uma disputa por poder. Tais sugestões me permitem, aliás, explicitar melhor o fato de que entendo o projeto de uma gramática moral dos conflitos sociais como mais apto a captar as formas de desreconhecimento. 
de reconhecimento. Em outras palavras, o limite no qual ele esbarra é o de adequadamente supor - muitas vezes apoiado em pesquisas que rastreiam antes os sentimentos de injustiça e os sofrimentos do mundo, ao invés de se limitarem aos discursos articulados de resistência, como em seu debate com Fraser (Honneth, 2003b) - uma realidade institucional na qual as expectativas de reconhecimento são confrontadas com uma realidade de desrespeito, sem, porém, dar o passo adicional de notar nesta realidade uma arena de conflitos que, por vezes, constrói ativamente o não reconhecimento, e não apenas ignora expectativas. Novamente, o caso da invisibilidade vem à mente, uma vez que, ali, a perspectiva analítica assumida por Honneth é a da ruptura da participação na vida social, graças à emergência de um sentimento interno de inadequação e não o da prática ativa levada a cabo por outros atores.

Então, em primeiro lugar, como explicam Saavedra e Sobottka (2009), a teoria honnethiana não é uma teoria comunitarista, como a interpreta Fraser, mas uma tentativa de encontrar uma linguagem apta a expressar os sentimentos de injustiça social. Esta linguagem é a linguagem do reconhecimento que, quando denegado naquelas esferas sociais do amor, do direito e da solidariedade, institucionaliza formas de desrespeito. Não se trata, portanto, de uma teoria psicológica e nem de uma teoria comunitarista, mas de uma teoria normativa, centrada nas implicações sociais de conquista ou denegação de reconhecimento recíproco. Em segundo lugar, tal gramática, inicialmente, é uma gramática relacionada a expectativas e não há indicação de que Honneth entenda o reconhecimento como algo que precede as relações sociais, de modo que é possível falar de desrespeito sem que isto implique em reverter o reconhecimento, isto é, em desreconhecer.

Assim, ainda que tenha nomeado este projeto de investigação sobre a luta por reconhecimento como uma gramática moral dos conflitos sociais, o fato de que Honneth centra sua atenção nos conflitos que buscam a conquista de reconhecimento intersubjetivo faz com que sua descrição da falta de reconhecimento enfatize os efeitos negativos para o desenvolvimento da personalidade individual: a ausência do reconhecimento nas esferas do amor, do direito e da solidariedade gera rupturas na autoconfiança, 
no autorrespeito e na autoestima dos sujeitos (2003a). Embora critique Fraser por não dar espaço aos sentimentos vindos da própria realidade dos atores sociais, segundo ele, um traço incontornável de uma Teoria Crítica, Honneth não contempla a luta contra o reconhecimento que organiza a realidade institucional na qual se luta por reconhecimento. Apenas posteriormente, em $O$ direito da liberdade (Honneth, 2011a), ele buscaria entender a corrupção de relações de reconhecimento recíproco como patologias sociais, isto é, práticas institucionalizadas que impedem os sujeitos envolvidos de perceberem o caráter social de sua ação e de suas relações ${ }^{3}$; patologias seriam distorções de segunda ordem, ou seja, falhas cognitivas quanto ao pano de fundo normativo no qual os sujeitos se encontram. Se, inicialmente, Honneth concentrara-se nos efeitos de relações distorcidas de reconhecimento sobre os indivíduos, agora ele se dedica a descrever situações nas quais esta distorção se institucionaliza e reproduz práticas falsas.

A passagem de um nível descritivo interacionista para um nível normativo marca uma importante mudança no projeto honnethiano, aliás. Como dito anteriormente, entre Luta por reconhecimento e O direito da liberdade, existe uma mudança no lugar ocupado pela noção de reconhecimento recíproco: de objeto - ou intenção - de conflito, esta categoria passa a fundamentar expectativas institucionalizadas. Isso só pode ocorrer porque, abrindo mão da obra de George Herbert Mead como sua referência para entender a formação da personalidade como um processo de conflito a respeito da realização de expectativas, Honneth (2011a) assume aquilo que chama de funcionalismo normativo, isto é, a abordagem segundo a qual uma esfera institucional não deve ser analisada por sua mera emergência e reprodução, mas sim que estas duas últimas devem ser entendidas com relação às normas e valores que são corporificados naquela esfera. Desse modo, numa tradição que remonta a Hegel e inclui Durkheim e Parsons, Honneth assume que a própria institucionalização de esferas de ação e reprodução da

${ }^{3}$ Honneth já utilizara o conceito de patologia social antes, no próprio Luta por reconhecimento. Em Das Recht der Freiheit, porém, as patologias sociais aparecem como formas institucionalizadas de falsa compreensão das relações sociais, de modo que atingem àqueles que as reproduzem tanto quanto àqueles que sofrem com seus efeitos. 
vida social depende de estas esferas aparecerem aos olhos dos envolvidos como legítimas. Este movimento, contudo, não é uma mera mudança de referência sociológica, uma vez que a dimensão normativa relacionada ao reconhecimento recíproco muda de posição e, com isso, a arquitetura teórica do projeto honnethiano se afasta da microssociologia em direção à teoria social normativa. Não por outra razão, os desconfortos sociais são apreendidos como patologias de segunda ordem (Honneth, 2011a; 2014) e não mais como conflitos de uma gramática moral. Consequentemente, uma primeira questão relativa à mudança operada por Honneth em seu modelo de uma teoria do reconhecimento diz respeito ao peso da filosofia e da teoria social normativas em comparação à análise propriamente sociológica. Deste sobrepeso resulta, porém, uma segunda limitação, referente à capacidade analítica deste modelo de apreender os conflitos sociais, já que se passou do nível do conflito intersubjetivo para o da disputa institucional.

Discussões recentes sobre formas distorcidas do reconhecimento, no entanto, parecem seguir pelo caminho oposto e demandar um entendimento mais refinado do lado negativo do reconhecimento (Martineau et al., 2012). Entre os autores mais próximos de Honneth, Arto Laitinen (2012), por exemplo, questiona a extensão atribuída por Honneth a esta ideia de distorção de segunda ordem e se pergunta se todas as formas de desconforto social poderiam ser explicadas por meio de um mal-entendido sobre o horizonte da vida ética. Heikki Ikäheimo (2015), por sua vez, mostra que existem pelo menos três causas para a ausência de reconhecimento: incapacidade, incompreensão e custos excessivos, sendo que os custos do reconhecimento podem ser uma barreira à atribuição de autoridade a um outro sujeito. Nicholas Smith e Jean-Philippe Deranty (2012), finalmente, argumentam que expressões de formas específicas de desconforto não devem ser lidas somente como patologias sociais da cognição, mas também como expressões de descontentamento com formas de organização social e política. Entre os autores menos próximos de Honneth, Barbara Kaletta (2008) procura mostrar como o reforço de laços de reconhecimento em situações de desintegração social podem exacerbar formas de animosidade entre grupos e Thomas 
Klikauer (2016) procura iluminar diferentes formas de desrespeito passíveis de ser encontradas dentro das relações de trabalho, propondo uma tipologia de formas distorcidas de reconhecimento que vá além daquelas identificadas por Honneth. Por fim, de um ponto de vista empírico Cinara Rosenfield, Luciana Mello e Andressa Corrêa procuram mostrar que a ideia de um princípio normativo organizador de todas as concepções de justiça não faz jus às diferentes representações sobre contribuições individuais ao bem-estar social encontradas entre os sujeitos (Rosenfield et al., 2015), algo que parece confirmar a crítica de Rutger Claassen (2014) a Honneth, segundo a qual este não consegue justificar a centralidade atribuída ao princípio normativo da liberdade social em sua teoria do reconhecimento.

Essas alternativas à teoria do reconhecimento, então, deixam perceber que não apenas o caminho da reconstrução normativa de práticas implícitas de reconhecimento e o diagnóstico de suas patologias são interessantes à teoria social, mas também uma variedade de análises que o tomam como um fenômeno da vida social e política, um elemento da forma como os sujeitos representam a si mesmos (Laitinen e Rosenfield, Mello e Corrêa), como eles organizam suas relações entre si e outros (Ikäheimo e Kaletta) ou suas relações políticas (Smith e Deranty, Klikauer, Claassen).

\section{Reconhecimento e demarcação simbólica}

A proposição de uma perspectiva explicativa desenvolvida a partir do reconhecimento como um fenômeno da vida social, então, visa contribuir para essas recentes discussões sobre o lado negativo do reconhecimento. No entanto, o abandono da reconstrução normativa trilhada por Honneth justifica-se também devido ao caráter eurocêntrico de sua análise (Pinzani, 2012) e ao fato de que seu conceito de reconhecimento tende a tal ponto a ser despido de conflitos que dificilmente se poderia imaginá-lo representando a pluralidade dos conflitos sociais da modernidade (Siep, 2012). Assim, ainda que a maioria das críticas e alternativas aqui mencionadas ressaltem o valor do insight honnethiano de que reconhecimento é uma necessidade básica da vida social (Honneth, 2003a), elas se afastam em diferentes medidas 
da tendência deste autor a ressaltar as implicações normativas do conceito de reconhecimento ${ }^{4}$. Ao ressaltar, pois, o lado negativo que as relações de reconhecimento - ou ainda: que a necessidade de reconhecimento - pode acarretar ao estabelecimento de relações entre diferentes atores e grupos sociais, é possível explicitar que o fenômeno social do reconhecimento, para além de suas implicações normativas, também está inserido em disputas por autoridade normativa e poder (McBride, 2013; McQueen 2015).

Esta perspectiva é chamada por alguns autores - particularmente McBride - de um modelo teórico da agência social e poderia ser apropriada por teorias sociológicas do reconhecimento. Nela, expectativas, representações e disputas cotidianas desempenham um papel tão relevante quanto o das normas implícitas de legitimação das esferas de sociabilidade e, por isso, seria possível articular a relação entre formas negativas de reconhecimento e práticas de demarcação simbólica que se expressam através do exercício de privilégios e posições de poder. Antes, porém, duas ressalvas se fazem necessárias. A primeira delas diz respeito ao fato de que a ideia de reconhecimento negativo, conforme tratada pela bibliografia citada acima, pode-se referir a diferentes práticas, como a denegação do reconhecimento, a atribuição de reconhecimento distorcido, ou ideológico, ou ainda à incapacidade de reconhecer aquilo que o sujeito considera digno de reconhecimento. Seria necessário, então, investigar estas diferenças a fim de esclarecer quais destas práticas podem posteriormente se revelar como práticas de demarcação simbólica através do exercício de posições de poder. Tal passo se faz tão mais necessário quanto é necessário ressaltar que, como um fenômeno cotidiano da vida coletiva, o conceito de reconhecimento deve ser capaz de explicar não apenas o progresso moral, como quer Honneth, mas também deve servir à explicação de situações em que o potencial de emancipação a ele associado

${ }^{4}$ Muitos autores se dedicaram, é certo, a seguir a trilha de análise aberta por Honneth. Também é certo que Honneth não ignora que exista uma dimensão negativa das sociedades modernas, uma dimensão que contraria a tendência histórica do progresso social. Seu tratamento do tema, contudo, não faz jus ao problema aqui apresentado como práticas e discursos de desreconhecimento. Pelo contrário: Honneth procura tratar do tema a partir de uma concepção organicista da sociedade (2014), de modo que os desenvolvimentos inesperados se revelem antes como paradoxos internos à modernidade (Hartmann; Honneth, 2006). 
se reverte. Isto porque, se este conceito possui um potencial crítico às formas de vida existentes, ele também pode representar uma forma de colonização de outros potenciais emancipatórios, como demonstra Beate Rössler (2007) ao tratar do reconhecimento financeiro como uma forma de comercialização de relações pessoais. Portanto, distorções do reconhecimento e práticas de negação do reconhecimento devem ser claramente separadas se se quiser entender sociologicamente quais intenções, emancipatórias ou regressivas, fazem parte das motivações de grupos estudados sociologicamente.

Ora, a prática, o discurso e a justificação do desreconhecimento são aqui tomadas como claramente regressivas, na medida em que objetivam corroer aquilo que legitima o potencial universalista e democrático das sociedades modernas, a saber, os princípios implícitos de reconhecimento e respeito mútuos e de solidariedade. Aqui cabe a segunda ressalva: a ideia de demarcação simbólica é um objeto clássico da sociologia e a ela nem sempre foi atribuído este caráter unilateralmente regressivo ${ }^{5}$. Para Max Weber (1922), a separação entre comunidade e sociedade se baseia na ereção de barreiras simbólicas, mas que remetem a horizontes diversos de expectativas dos envolvidos com relação aos seus parceiros de interação. Norbert Elias (2001), por sua vez, viu no processo de distinção entre a corte francesa e as classes burguesas ascendentes um processo ambíguo segundo o qual também os grupos em posições simbolicamente favoráveis se tornavam prisioneiros das práticas introjetadas de civilização. Por fim, Pierre Bourdieu (2007) procurou demonstrar como estas barreiras serviriam antes ao reforço da posição privilegiada de certos grupos, os quais exerceriam sua capacidade de se distinguir, por meio da aquisição do capital simbólico que os diferenciaria daqueles que não estavam em condição de adquirir este capital.

Mais recentemente, todavia, a noção de demarcação simbólica foi apropriada de outro modo. Em um artigo no qual se dedica a explorar

5 Não se pretende, neste artigo, desenvolver uma teoria da demarcação simbólica. Como dito, o tema é objeto da teoria social há muito tempo. Os exemplos dados aqui servem como referência ao fato de que um problema tão relevante da integração das sociedades modernas, e um problema do qual a teoria do reconhecimento honnethiana passa ao largo, chama a atenção para a dimensão negativa do reconhecimento de que tratarei nesta seção do artigo. 
prospectivamente aquilo que certa literatura sociológica chama de tendência à barbarização, Claus Offe (1996), oferece um diagnóstico de um "micro estado de natureza", isto é, de uma competição generalizada entre os indivíduos, no qual as conquistas institucionais das sociedades modernas seriam confrontadas por uma luta mais ou menos ampla entre três grupos distintos internos a estas sociedades: os vencedores, isto é, aqueles com acesso às garantias institucionais da seguridade e do respeito; os perdedores, isto é, aqueles cujo acesso a estas garantias é descontínuo e incerto e dos quais os vencedores procuram se distinguir por meio do reforço às suas posições de seguridade; e os não habilitados a participar, isto é, a massa de pessoas desqualificadas a participar em arenas públicas de disputas meritocráticas institucionalmente reconhecidas em um sistema de mercado (num contexto brasileiro, estes grupos poderiam ser representados por desempregados, agricultores de subsistência, camponeses e índios isolados etc.). Offe, aqui, apresenta um diagnóstico que foi mais tarde retrabalhado e reapresentado por Honneth como uma barbarização do conflito social (2011b), isto é, uma desregulação das normas recíprocas de reconhecimento, de acordo com a qual a reciprocidade dá lugar à competição, a solidariedade à desincumbência e o reconhecimento ao entrincheiramento. Para Honneth e Offe, porém, esta barbarização aparece como um diagnóstico, justamente porque ambos veem a desregulação das lutas por reconhecimento como uma característica de um momento específico da modernidade. Nesse sentido, ambos se mantêm fiéis à compreensão normativa do reconhecimento como o princípio regulador da sociabilidade na modernidade.

Outros autores, no entanto, se afastam desta ideia e apresentam as relações de reconhecimento como lutas pelo estabelecimento de hegemonias acerca de interpretações e representações normativas da vida coletiva (McBride, 2013). A partir disto, a disputa pelo reconhecimento e o estabelecimento de barreiras simbólicas deixa de ter o caráter de um mero diagnóstico ou de um momento de sociabilidade desregulada e passa a fazer parte da paisagem dos conflitos sociais imanentes às sociedades plurais que emergem no período moderno. Esta busca pela hegemonia entre 
diferentes representações da vida coletiva e interpretações dos horizontes de sociabilidade é, de acordo com Jeffrey C. Alexander (2006), um elemento de estruturação do discurso civil. Para Alexander, esta disputa discursiva é expressa por meio das categorias de pureza e impureza, ou seja, através da ideia de que determinados indivíduos ou grupos possuem características às quais se atribui reconhecimento, respeito e solidariedade, enquanto a outros grupos, os impuros, estas atribuições são justificadamente negadas, já que estes não se enquadram na representação ideal de parceiros da vida civil e nem contribuem para aquilo que é interpretado como objetivos coletivos. Esta distinção entre puros e impuros pode ser traduzida de modo a representar uma forma de estruturação discursiva da demarcação simbólica, mas as categorias de pureza e impureza também remetem à formulação de uma comunidade imaginada ideal (Anderson, 1983), à qual os indivíduos atribuem o status de pureza e da qual buscam excluir os impuros por meio do recurso a uma justificação normativa da exclusão ou da ereção das barreiras.

O princípio através do qual estas barreiras mencionadas são erigidas é, pois, um recurso utilizado para demarcar identidade e diferença; todavia, este princípio apenas desempenha um papel especificamente regressivo para agora adotar um vocabulário mais próprio à Teoria Crítica da Escola de Frankfurt - se for demonstrado que esta demarcação simbólica representa uma ferida às pretensões normativas das sociedades modernas. Porém, nem Alexander, nem McBride e nem nenhum dos sociólogos mencionados acima adota um método reconstrutivo que permita identificar nas esferas institucionalizadas de ação social uma pretensão normativa. De fato, entre os citados, é justamente Honneth o único que o faz. Portanto, é por meio de uma nova remissão à sua teoria da legitimidade, através de relações implícitas de reconhecimento recíproco, que se podem caracterizar estas formas discursivas de demarcação simbólica como formas que negam valores implícitos da modernidade. É por isso que o conceito de desreconhecimento proposto aqui difere daquilo que é exposto por McBride, por exemplo. Enquanto este último tende a entender tanto a fenomenologia quanto a normatividade do reconhecimento num sentido próximo à disputa por 
poder simbólico interna a um campo de ação social, conforme descrita por Bourdieu, falar de um princípio de desreconhecimento implica identificar conceitualmente uma forma discursiva e prática que renega não somente (no nível fenomenológico) um grupo, mas também (no nível normativo) uma lógica de legitimação da modernidade; implica também, então, admitir a normatividade do reconhecimento como uma lógica de legitimação, como faz Honneth. É a este princípio que organiza normativamente práticas concretas que se está chamando desreconhecimento.

Resta ainda indicar, ao menos prospectivamente, se este conceito é representativo de práticas sociais sistemáticas. Aqui parece razoável retomar a ideia de uma comunidade imaginada. O recurso a esta comunidade imaginada de indivíduos puros, para justificar a aplicação deste princípio de desreconhecimento, serve ao propósito de fornecer uma justificativa para as barreiras simbólicas entre diferentes grupos e pode, como fica claro em seu uso como discurso político do "cidadão de bem", do "pagador de impostos" ou do "trabalhador honesto", ser utilizado também para expressar considerações políticas sobre a vida coletiva, e não apenas sobre a identidade ou o valor de certos grupos ${ }^{6}$. Como foi demonstrado acima, porém, o princípio do desreconhecimento implica mais do que a mera separação simbólica, mas uma tentativa de solapar aquelas bases implícitas da sociabilidade moderna expressas no reconhecimento recíproco. Assim, articular a dimensão negativa do reconhecimento e as práticas de demarcação simbólica implica em, por um lado, expor em que medida aquelas práticas cotidianas do reconhecimento negativo se associam a uma negação do reconhecimento e, por outro lado, expor em que medida essa negação se expressa como um exercício de poder por parte dos grupos e indivíduos

${ }^{6}$ É claro que, em muitos casos, a mistura entre os discursos identitários e os discursos políticos existe. Basta pensarmos na associação entre pobres que não trabalham e não pagam impostos, no racismo e no preconceito regional existentes no Brasil. A exposição destas categorias de modo desanuviado visa apenas simplificar o entendimento. Além disso, limpar este meio de campo é também uma das tarefas que o desenvolvimento de um modelo teórico deve enfrentar. No mais, a esta altura, já deve também estar claro que muitas formas de demarcação simbólica também são traduzidas de forma prática, como nas distinções entre morro e asfalto ou entre os dois lados do rio (no Rio de Janeiro e em São Paulo, respectivamente). 
melhor posicionados em determinadas situações. A fim de completar estes objetivos, até o momento já foi demonstrado como as práticas de hierarquização e negação absoluta do reconhecimento operam como discursos de exclusão simbólica de certos grupos e indivíduos das arenas institucionalizadas de reconhecimento. Em adição às formas de exclusão prática (de acesso a serviços, de acesso a riquezas, de acesso à segurança etc.) formas de desreconhecimento procuram solapar o reconhecimento implícito da universalidade do respeito e da solidariedade modernas. Uma vez que as relações de reconhecimento são antes abstratas, o princípio de negação destas relações também se expressa de modo simbólico. Assim, a demarcação simbólica mostra-se em pelos menos dois casos: a animosidade dirigida a certos grupos e a naturalização das desigualdades.

\section{Desreconhecimento como negação dos princípios normativos da modernidade}

No caso da animosidade dirigida a grupos, como demonstra Kaletta (2008), a desintegração de laços sociais propicia uma situação na qual a legitimidade do tecido de reconhecimento das sociedades acaba se esgarçando e levando grupos mais bem posicionados a lutar pela manutenção de seu status. A crise das relações do reconhecimento se expressa, neste caso, no desenvolvimento de imagens do outro, num movimento inverso ao da simbolização de uma comunidade imaginada: ao invés de defender seu grupo por meio de um reforço da própria pureza, os grupos ameaçados formulam e estereotipam aqueles sobre os quais conseguem exercer poder, de modo que a substituição do reconhecimento pelo entrincheiramento de grupos privilegiados em suas posições vem acompanhada da emergência daquilo que a autora chama de animosidade dirigida a grupos. Com este conceito, ela procura descrever a passagem da desintegração social para a negação do reconhecimento (Kaletta usa o termo depreciação) como uma passagem à animosidade simbolicamente justificada. Um caso particular deste tipo de animosidade simbolicamente justificada é descrito pelo antropólogo sérvio Ivan Čolović (2002) ao estudar o comportamento de 
torcedores de futebol nacionalistas durante a implosão da ex-lugoslávia: de acordo com Čolović, hooligans sérvios e croatas ajudaram a fomentar movimentos antifederalistas no país, através do recurso a discursos de negação do valor da outra nacionalidade. No caso do conflito iugoslavo, mostra Čolović, a demarcação de barreiras entre sérvios e croatas se dava não apenas por meio da valorização da própria nacionalidade, mas também por meio do acúmulo de um "capital simbólico de ódio" (2002, p. 280) quanto a outros grupos nacionais constituintes da ex-lugoslávia. Assim, o chauvinismo e a capacidade de expressá-lo tornavam-se ativos simbólicos aos quais os grupos recorriam a fim de reforçar sua posição central no imaginário nacional e, por oposição àqueles representados como diferentes ${ }^{7}$, demarcar barreiras de reconhecimento e desreconhecimento.

O caso da demarcação através da naturalização das desigualdades, ao contrário do anterior, é um caso eminentemente associado à formação da sociedade brasileira. De acordo com a análise de Roberto Schwarz ([1977] 2012), desde o início da difusão dos ideais liberais na Europa, estas encontraram terreno fértil no Brasil, sendo professadas por intelectuais e políticos que, apesar disso, sustentavam uma estrutura social escravista e, no que se refere aos não escravos, hierárquica. Este liberalismo fora do lugar, de acordo com o autor, foi a forma social que se pôde, naquele momento, legitimar - ainda que Schwarz ressalte seu caráter ideológico. De todo modo, a manutenção da escravidão e a cultura do favor demonstravam a apropriação da lógica do liberalismo moderno (que é a mesma lógica do reconhecimento) pela lógica da arbitrariedade e do interesse particular. O resultado, um sistema peculiar de coexistência estável entre pessoas de diferentes níveis de status, baseava-se na capacidade da formação social resultante de oferecer compensação simbólica para a falta de universalismo efetivo. Este sistema, uma nova topografia social mais do que uma desordem social, de acordo com Schwarz, poderia ser expresso

${ }_{7}$ Gordy (2009) analisa um caso semelhante de distinção entre um grupo que representa a si mesmo como defensor da nação e um grupo estereotipado como traidor da pátria: aqueles que ouviam a 'nova música tradicional sérvia', patrocinada por Slobodan Milošević, e aqueles que ouviam o rock'n'roll internacional e que faziam de Belgrado uma cidade cosmopolita. 
através da linguagem do reconhecimento: na medida em que as hostilidades são substituídas pelo favor, a reciprocidade é substituída por uma forma de prestação de contas que preserva as hierarquias e as estratificações, de modo que as relações de reconhecimento funcionam antes como uma forma de legitimação destas hierarquias ${ }^{8}$. Essas desigualdades de status permaneceriam um traço fundamental da sociedade brasileira, mesmo após a modernização ocorrida ao longo do século XX, segundo Jessé Souza (2006). O resultado foi a naturalização da ideia de que, em sociedades periféricas, certas classes possuem acesso desigual às esferas de cidadania (ou de reconhecimento, no vocabulário empregado aqui), ou sequer possuem acesso a estas esferas, ou seja, a naturalização da subcidadania. Este traço, que se desvia do processo esperado nas sociedades modernas - ou melhor, daquilo que Honneth espera encontrar ao empreender uma reconstrução normativa dos princípios do moderno liberalismo -, é um indicativo de que o processo de racionalização do mundo ocidental nem sempre é acompanhado pela constituição de esferas que institucionalizam os princípios orientadores deste liberalismo universalista e democrático. Se, por um lado, esta dinâmica resulta em uma forma distorcida de reconhecimento, baseado na legitimação da hierarquização, por outro lado, ela também gera uma forma de preconceito contra um tipo de personalidade considerada disruptiva ou improdutiva, um preconceito contra os subcidadãos ${ }^{9}$. Ora,

8 Schwarz (2012 [1977], p. 23) efetivamente usa o termo "reconhecimento" ao tratar da compensação simbólica, mas o faz para descrever como a relação do favor aparece, aos olhos daqueles que a vivenciam em ambos os lados, não apenas como legítima, mas principalmente como bem-intencionada. A análise aprofundada deste "reconhecimento fora do lugar", ainda que se sugira muito propícia à investigação, não poderá ser feita aqui, já que esta seção sequer pretende comprovar empiricamente a ideia do desreconhecimento, e sim, dada a limitação do artigo, ilustrá-la analiticamente.

${ }^{9}$ Aqui me parece que o casamento operado por Souza entre poder e moralidade se expressa pelo lado negativo: o poder de constituir uma imagem moral sobre uma parcela dos indivíduos. A disposição deste poder não é contrária à forma como procurei apresentar o conceito de desreconhecimento, pelo contrário: na medida em que naturaliza a incapacidade de alguns grupos acessarem a vida coletiva, o processo descrito por Souza lhes nega a possibilidade de participar de esferas de reciprocidade. Além disso, é interessante ressaltar que Souza (2006, p. 47) parece tratar do tema, porém usando o termo "des-conhecer" para tratar do fenômeno. Dada a reconstrução da teoria do reconhecimento exposta acima, resulta óbvio que desconhecer é um vocábulo menos apropriado para tratar da mesma ideia. 
ainda que o foco de Souza seja a noção de um "habitus precário" que permeia a institucionalização da cidadania no Brasil, parece claro que seu modelo analítico ambiciona apresentar tal processo como uma teoria do reconhecimento e, especificamente, como uma teoria do reconhecimento na qual se atenta para a performance ativa de relações de subordinação. Nesse sentido é que se pode ilustrar - e sugerir a viabilidade de uma tal pesquisa em lugar propício - a ideia de desreconhecimento, por meio da articulação das interpretações de Schwarz e Souza a respeito da posição estrutural ocupada por grupos e pessoas desprovidas de um estatuto de igualdade substancial (dado que, formalmente, vige a cidadania igualitária). É justamente a constituição de um imaginário coletivo que lhes atribui a pecha de incapazes ou inúteis, que poderia, também, ser analisada por meio do recurso à ideia do desreconhecimento, uma vez que aqui se está a falar do estabelecimento de uma diferenciação simbólica entre aqueles que estão aptos a participar das esferas institucionais da meritocracia e do direito e aqueles a quem esta participação é simbolicamente negada (ainda que, por vezes, seja tolerada na prática, como se nota em certos comentários pós-eleitorais de alguns meios de comunicação tradicionalmente associados à elite brasileira). Dessa maneira, também a naturalização da subcidadania pode ser entendida na mesma chave que os discursos de negação do liberalismo moderno, uma negação que poderia ser traduzida pelos conceitos de reconhecimento e desreconhecimento.

Finalmente, esta ilustração permite retomar a diferença entre tal categoria analítica e as formas de desrespeito tratadas por Honneth em Luta por reconhecimento. Como aludido na primeira seção do artigo, ali se tratava de reconfigurar os espaços institucionais de modo a torná-los condizentes com as expectativas dos participantes; neste caso, porém, o esquema da passagem à modernidade, como demonstrado na segunda esfera de reconhecimento mencionada por Honneth, é implicitamente mediado pela universalização do estatuto de cidadania. São exatamente as normas e valores que sustentam este estatuto igualitário e universalista que as interpretações da sociedade brasileira mobilizadas aqui, mostram ser ativamente desreconhecidas. 


\section{Conclusão}

Ainda que a demarcação simbólica e a naturalização da subcidadania sejam temas clássicos da teoria social, especialmente no Brasil, poucos estudos se dedicaram a compreender as dinâmicas por meio das quais grupos estabelecem e justificam para si mesmos aquela diferenciação social e, particularmente, nenhum dentro da perspectiva do reconhecimento ${ }^{\mathbf{1 0}}$. Ainda mais especificamente, nenhum estudo investigou, do ponto de vista do reconhecimento, quais são as justificativas morais que grupos favorecidos mobilizam e utilizam como justificativa para se diferenciarem de outros grupos que se encontram em situação socialmente inferior. Nesse sentido, a hipótese aqui apresentada, de que um princípio de desreconhecimento é o que estrutura estas práticas, representa uma tentativa de contribuir para os debates sobre o lado negativo do reconhecimento, que envolve uma apropriação mais sociológica do que filosófica deste conceito. De modo geral, o princípio aqui exposto se diferencia de outras teorias do lado negativo do reconhecimento, porque admite que o ponto de partida em uma teoria reconstrutiva tem a vantagem de expor de modo satisfatório os mecanismos de legitimação das normas e valores modernos, embora falhe em apreender a gramática moral dos conflitos sociais. Assim, em sua obra madura, Honneth ganha uma melhor compreensão da reprodução institucional das sociedades, mas perde o acesso às experiências de injustiça, substituindo-as, como fundamento da crítica social, pela noção de patologia social. Nesse sentido, mesmo admitindo a relevância da crítica de McBride e outros a Honneth, no que se refere à apreensão de conflitos que revelam o lado negativo do reconhecimento, o modelo normativo do reconhecimento ainda pareceu mais adequado à compreensão dos processos integrativos do que o modelo da ação. Por outro lado, o sobrepeso analítico atribuído por Honneth à legitimação normativa acaba por limitar seu acesso às dinâmicas sociológicas de exercício do poder, em especial àquelas em que o reconhecimento é utilizado de modo perverso, como na animosidade dirigida a grupos, ou

10 Jessé Souza remete à teoria do reconhecimento de Taylor, mas sua principal referência teórica é Bourdieu. 
ainda naquelas em que o padrão normativo de reconhecimento se encontra fora do lugar, como no caso da subcidadania. Ao fim e ao cabo, este artigo espera ter contribuído conceitualmente com a discussão sobre a análise do lado negativo do reconhecimento por meio da sugestão de um princípio de desreconhecimento que dê forma analítica a uma série de práticas sistematicamente encontradas em sociedades modernas.

Luiz Gustavo da Cunha de Souza é professor de Sociologia na Universidade Federal de Santa Catarina.

”gustavo.cunha.s@ufsc.br

\section{Referências}

1. ALEXANDER, Jeffrey C. The civil sphere. Nova York: Oxford University Press, 2006.

2. ANDERSON, Benedict. Imagined communities: reflections on the origins and spread of nationalism. Londres/Nova York: Verso, 1983.

3. BOURDIEU, Pierre. A distinção. Crítica social do julgamento. São Paulo: Edusp/Porto Alegre: Zouk, 2007.

4. CLAASSEN, Rutger. Social freedom and the demands of justice: a study of Honneth's Recht der Freiheit, Constellations, v. 21, n. 1, p. 67-82, 2014.

5. ČOLOVIĆ, Ivan. Politics of identity in Serbia. Essays in political anthropology. Nova York: New York University Press, 2002.

6. ELIAS, Norbert. A sociedade de corte: investigação sobre a sociologia da realeza e da aristocracia de corte. Rio de Janeiro: Zahar, 2001.

7. FRASER, Nancy. From redistribution to recognition? Dilemmas of justice in a post-Socialist age. New Left Review, v. 1, n. 212, p. 68-93, jul.-ago. 1995.

8. FRASER, Nancy. Social justice in the age of identity politics: redistribution, recognition and participation. In: FRASER, Nancy; HONNETH, Axel. Redistribution or recognition? A political-philosophical exchange. Londres/Nova York: Verso, 2003a, p. 7-108.

9. FRASER, Nancy. Distorted beyond all recognition: a response to Axel Honneth. In: FRASER, Nancy; HONNETH, Axel. Redistribution or recognition? A politicalphilosophical exchange. Londres/Nova York: Verso, 2003b, p. 198-235.

10. GORDY, Eric D. The culture of power in Serbia. Nationalism and the destruction of alternatives. Philadelphia: University of Pennsylvania Press, 2009. 
11. HARTMANN, Martin; HONNETH, Axel. Paradoxes of capitalism. Constellations, v. 13, n. 1, p. 41-58, 2006.

12. HONNETH, Axel. Die soziale dynamik von mißachtung. Zur ortbestimmung einer kritischen gesellschaftstheorie. In: HONNETH, Axel. Das andere der gerechtigkeit. Aufsätze zur praktischen philosophie. Frankfurt: Suhrkamp, 2000, p. 88-109.

13. HONNETH, Axel. Kampf um anerkennung. Zur moralischen grammatik sozialer konflikte. Mit einem neuen Nachwort. Frankfurt: Suhrkamp, [1994] 2003a.

14. HONNETH, Axel. Umverteilung als anerkennung. Eine erwiderung auf Nancy Fraser. In: FRASER, Nancy; HONNETH, Axel. Umverteilung oder anerkennung? Eine politisch-philosophische kontroverse. Frankfurt: Suhrkamp, 2003 b.

15. HONNETH, Axel. Unischtibarkeit. Stationen einer theorie der intersubjektivität. Frankfurt: Suhrkamp, 2003c.

16. HONNETH, Axel. Recognition and ideology. In: VAN DER BRINK, Bert; OWEN, David (Orgs.). Recognition and power. Axel Honneth and the tradition of critical social theory. Cambridge: Cambridge University Press, 2007, p. 323-47.

17. HONNETH, Axel. Das recht der freiheit. Grundriß einer demokratischen sittlichkeit. Berlin: Suhrkamp, 2011 a.

18. HONNETH, Axel. Verwilderungen des sozialen konflikts. Anerkennungskämpfe zu beginn des 21. Jahrhunderts. MPIfG Working Paper. Colônia: Max-PlanckInstitut für Gesellschaftsforschung, 2011b.

19. HONNETH, Axel. Die krankenheiten der gesellschaft. Annäherung an einen nahezu unmöglichen begriff. Westend. Neue zeitschrift für sozialforschung. Frankfurt, v. 1, p. 45-60, 2014.

20. IK ̈̈HEIMO, Heikki. Conceptualizing the causes for the lack of recognition: capacities, costs and udnerstanding. Studies in social and political thought, $\mathrm{v}$. 25, Special issue: Pathologies of recognition, p. 25-43, 2015.

21. KALETTA, Barbara. Anerkennung oder abwertung. Über die Verarbeitung sozialer Desintegration. Wiesbaden: VS Verlag für Sozialwissenschaften, 2008.

22. KLIKAUER, Thomas. Negative recognition: Master and slave in the working place. Thesis Eleven, v. 132, n.1, p. 39-49, 2016.

23. LAITINEN, Arto. Misrecognition, misrecognition, and fallibility. Res publica, $v$. 18, n. 1, p. 25-38, 2012.

24. MARTINEAU, Wendy, MEER, Nasar, THOMPSON, Simon. Theory and practice in the politics of recognition and misrecognition. Res Publica, v. 18, p. 1-9, 2012.

25. MCBRIDE, Cillian. Recognition. Key political concepts. Cambridge/Malden: Polity press, 2013.

26. MCQUEEN, Paddy. Honneth, Butler and the ambivalent effects of recognition. Res publica, v. 21, n. 1, p. 43-60, 2015. 
27. OFFE, Claus. Moderne barbarei: der naturzustand im kleinformat? In: MILLER, Max; SOEFFNER, Hans-Georg (Orgs.). Modernität und barbarei. Soziologische Zeitdiagnose am Ende des 20. Jahrhunderts. Frankfurt: Suhrkamp, 1996.

28. PINZANI, Alessandro. O valor da liberdade na sociedade contemporânea. Novos estudos CEBRAP, São Paulo, v. 94, p. 207-15, 2012.

29. ROSENFIELD, Cinara L.; MELLO, Luciana Garcia de; CORRÊA, Andressa S. Reconstrução normativa em Axel Honneth e os múltiplos justos no mercado de trabalho. Civitas. Revista de ciências sociais, Porto Alegre, v. 15, n. 4, p. 664-85, out./dez., 2015.

30. RÖSSLER, Beate. Work, recognition, emancipation. In: VAN DER BRINK, Bert; OWEN, David (Orgs.). Recognition and power. Axel Honneth and the tradition of critical social theory. Cambridge: Cambridge University Press, 2007, p. 135-63.

31. SAAVEDRA, Giovani A., SOBOTTKA, Emil A. Discursos filosóficos do reconhecimento. Civitas. Revista de ciências sociais, Porto Alegre, v. 9, n. 3, p. 386-401, set./dez., 2009.

32. SCHWARZ, Roberto. As ideias fora do lugar. In: SCHWARZ, Roberto. Ao vencedor as batatas. Forma literária e processo social nos inícios do romance brasileiro. São Paulo: Editora 34/Duas Cidades, [1977] 2012.

33. SIEP, Ludwig. Mutual recognition: Hegel and beyond In: IKÄHEIMO, Heikki; LAITINEN, Arto (Orgs.). Recognition and social ontology. Leida/Boston: Brill, 2011, p. 117-44.

34. SMITH, Nicholas; DERANTY. Jean-Philippe. Work and the politics of misrecognition. Res Publica, v. 18, p. 18-53, 2012.

35. SOUZA, Jessé. A construção social da subcidadania. Por uma sociologia política da modernidade periférica. Belo Horizonte: Editora UFMG/Rio de Janeiro: IUPERJ, 2006.

36. TAYLOR, Charles. Multikulturalismus und die politik der anerkennung. Frankfurt: Suhrkamp, 2009.

37. WEBER, Max. Vergemeinschaftung und vergesellschaftung. In: WEBER, Max. Wirtschaft und gesellschaft. Grundriß der sozialökonomik. III abteilung. Tübingen: J.C.B. Mohr (Paul Sibeck), 1922. 